\title{
Public health medicine and primary health care: convergent, divergent, or parallel paths?
}

Historically, general medical practitioners* and public health doctors $\dagger$ have striven for health goals by different means. General practice has concentrated on personal, continuing health care focused on the consultation, usually at the request of the patient. Public health doctors $†$ have emphasised changes in the environment, society, and health service provision and organisation as the basis of interventions impacting on whole populations, or on marginalised groups of the population.

Changes in medical practice, social and health care organisation, and political and public expectation have forced a radical reappraisal of the traditional relationship between these two branches of medical practice. These changes include the incorporation within general practice of staff such as health visitors and district nurses spurring on the concept of primary health care ${ }^{1}$ the deliberate and successful shift, continuing to gather momentum, towards preventive health care in general practice $;^{23}$ and the move towards greater administrative involvement of general practitioners in the management, organisation, and development of health services, hastened by the NHS reforms and best exemplified by fund holding general practices. ${ }^{4-6}$

The increasing focus of public health medicine on the assessment of health and health care needs, the development of policy and strategy, the promotion of health, the control and prevention of disease, and the organisation of services (activities undertaken at the expense, in practice if not in principle, of the control of environmental hazards and the advocacy role) has coincided with these changes in general practice. ${ }^{7-9}$

In the UK the fusion of the district and family health services authorities, and the increasing involvement of general practitioners in commissioning, and the requirement of health authority staff to support general practice commissioners make a strong relationship between the two medial specialties essential. ${ }^{5}$ In what direction has the relationship been moving?

\section{Relationship between general practice and public health medicine: literature review}

The relationship in Britain between the two specialties have been reviewed on many occasions in the past 20 or so years. ${ }^{7-18}$ With one exception, Tudor-Hart, ${ }^{15}$ who proposes that general practice simply takes over the public health function, authors call for closer working relationships between the specialties, pointing to the mutual benefits. Mant and Anderson conclude that integration of public health medicine and general practice could make the former specialty unnecessary. The work cited here,

* Increasingly general practice is referred to, in Britain, as primary health care. As such, the terms are used interchangeably here. General practice is usually referred to as family medicine in the USA.

t Previously known in Britain as community medicine specialists; the term community medicine, widely used in other countries, is the equivalent of public health medicine in Britain. referring to Britain, ${ }^{7-18}$ and abroad, ${ }^{19-23}$ can be reviewed only briefly, but one message dominates: the benefits of collaboration have long been recognised, ${ }^{910}$ but patchily achieved, ${ }^{11131518}$ despite a huge shift of public health work into general practice, contributing to its redevelopment as primary health care. ${ }^{1217}$

Working for the integration of health services was perceived as a key role for public health doctors when the specialty was reviewed before the 1974 NHS reorganisation and the need for a close relationship with general practice was clearly essential to fulfil the role. ${ }^{9}$ Public health doctors saw the huge potential for collecting epidemiological data for both planning and research purposes, a potential so ably demonstrated by Will Pickles, as discussed by Parry, ${ }^{10}$ and many other general practitioners. ${ }^{24}$ The arguments in favour of collaboration were indisputable, and clearly articulated, but the spheres of influence of general practice and public health may have separated, rather than converged, in the 1970 s and early 1980 s, with general practitioners focusing on the consultation and the individual patient, and public health on national, regional, and district health authority concerns.

The frustration of public health oriented primary care doctors was openly declared by Tudor-Hart, who wrote:

"It is true that the public health tradition, here as in most countries, has been impoverished by its divorce from clinical medicine.... Under any circumstances community medicine will take time to recover from a century of banishment to the periphery of medical practice, but clinicians will also take time to recover from their ignorance of the tasks of organisation, management, local planning, and research based clinical strategy." 11

Later, he developed the argument that general practice ought to perform the public health function, and calculated a minimum requirement of public health professional time of three sessions per week per 10000 registered patients ${ }^{15}$ (equivalent to about 1500 staff, and more than the entire establishment of public health medicine in the UK at present). Similar arguments in favour of public health oriented primary health care were made by Mant and Anderson. ${ }^{12}$

In 1987, Stone reviewed the arguments for a convergence of public and primary care and warned that, while the need was clear, there were major obstacles in the way. ${ }^{13}$ He wrote, "Ideologically, the worlds of general practice and public health remain firmly separated and occasionally in conflict." He referred to the separation caused by organisational and geographical boundaries and the problems of specialties jostling for position. His article identified as a focus for convergence the need for individual and population based interventions for effective prevention.

Russell outlined a broad but practical agenda for the public health doctor working with primary health care, including making personal contact, finding out what help general practitioners want from public health, and keeping them informed about local population health problems. ${ }^{14}$ Russell's concept of the public health role in primary care 
Table 1 Some resources of public health and primary health care

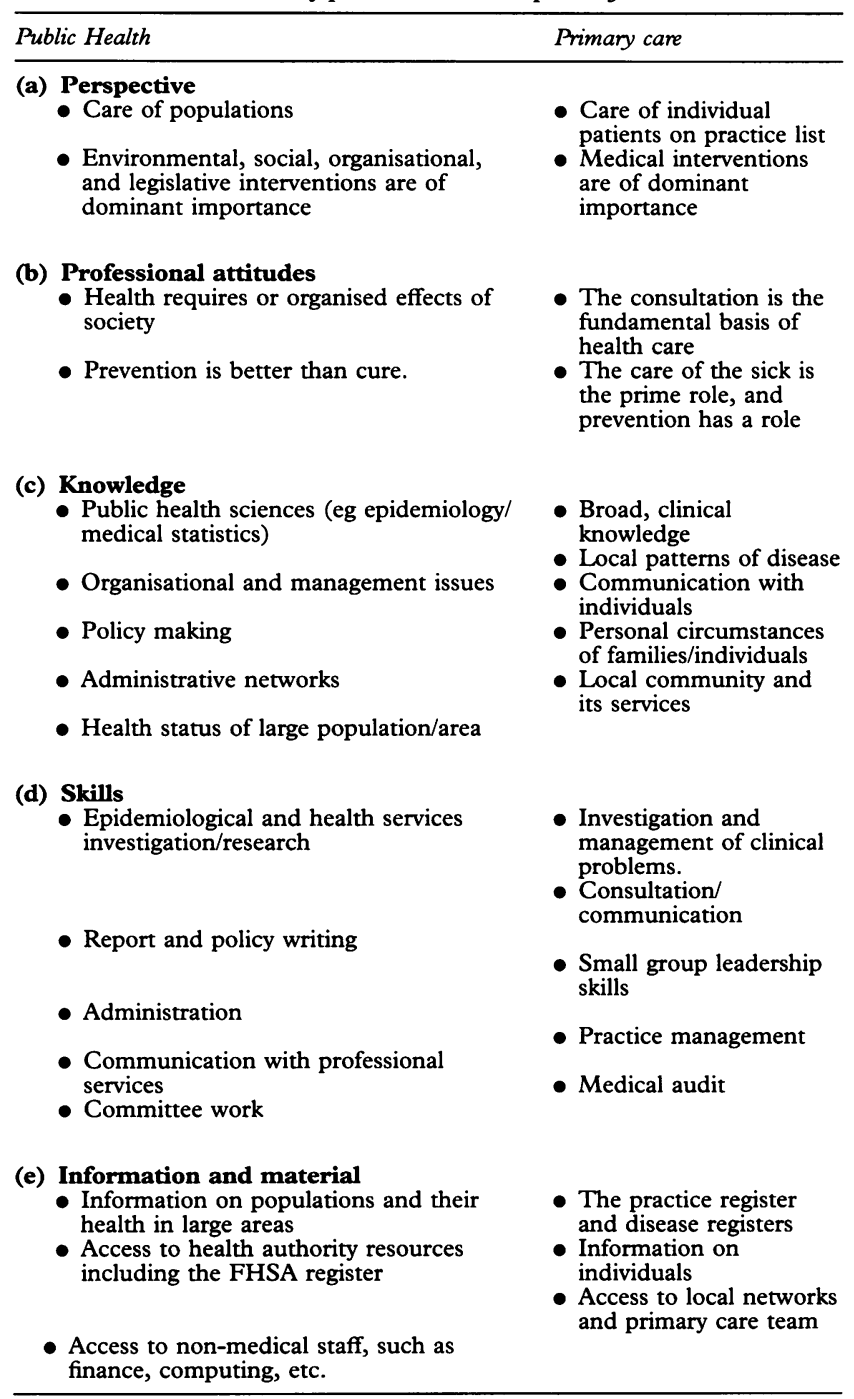

FHSA $=$ family health services authority

was constructed around a support function, and being an "architect of desirable change...". By contrast, Ashton's grander scheme ${ }^{16}$ concerned the public health role within the World Health Organisation's broad vision of primary health care ${ }^{25}$ including: environmental change, health education, preventive care, and personal services. ${ }^{16}$ Clearly, a public health and primary care partnership within his vision would require major changes in general practice and not simply the accommodation of public health. Ashton presented four caveats to the assumption that most public health work can be done in primary health care. These are summarised as follows:

(1) The primary health care concept of health promotion would be too narrow;

(2) Many staff in primary health care would not be motivated to public health work;

(3) There will remain tasks which could not be done at primary care level (for example, health strategy);

(4) The conflict between individual and collective health cannot be resolved except by separating the roles of advocate, mediator, and enabler.

Surprisingly, and disappointingly, despite 20 years of analysis and rhetoric, a massive shift of preventive care and health promotion into primary care, ${ }^{17}$ and action by enthusiasts, the two specialties were judged too far apart in an editorial by Hannay, ${ }^{18}$ who suggested joint appointments and training as a means of avoiding the divergent career pathways of general practice and public health medicine.

The position in the UK, with its strong tradition of medically oriented public health practice, is unlikely to be worse than in other countries. The academic literature in English on the specific subject of collaboration between public health and primary health care is dominated by papers by UK authors. Hellberg identifies intersectoral and interprofessional action as one of the greatest public health challenges in Europe. ${ }^{26}$

Kark's broad vision of an integrated practice of epidemiology, public health, and community orientated health care, ${ }^{19}$ has influenced medical education and practice in Israel and has elicited widespread interest in the USA and elsewhere, as reviewed by Abramson. ${ }^{2122}$ As a generalisation, however, in Israel and even in the USA where to avert "... impending disaster and provide personal health care to those rejected by the rest of the health system"23 remains the responsibility of public health, the dominant spheres of interest and influence of practitioners of public health and practitioners of family medicine/primary health care remain separate.

Only in some parts of the developing world does the practice of public health and primary health care truly merge, as demonstrated in many projects. ${ }^{27}$ There imperative and motivation come from the lack of financial resources and health care personnel. ${ }^{28}$ The imperative of acute health care there forces many public health doctors to undertake clinical work, sometimes to the detriment of their public health role. Furthermore, most clinical practice remains distanced from public health.

The remainder of this paper analyses the arguments in favour of an alliance from a pragmatic viewpoint.

\section{Resources and skills of public health and general practice}

Table 1 lists some of the core perspectives, attitudes, knowledge, skills, and resources of the two branches of medical practice. It is immediately apparent that the two are complementary. Only the most exceptional individual could lay personal claim on having all these resources. While techniques and skills can be acquired by hard work, the perspectives, attitudes, ethics, political knowledge, networks, and understanding of the power structures are acquired by long experience. The differing perspectives and attitudes held by, and probably required of, public health medicine and general practice are not incompatible, but dissonance is inescapable.

\section{The common agenda}

Ultimately, the professional goals of public health medicine and general practice are the same - improvement in the health, in its broadest sense, of the populations they serve. The methods and approaches of the specialties differ. In public health there is an ill defined boundary as to the acceptable in terms of professional intervention and while the public health goal does not change, the approach constantly shifts and sometimes radically so. ${ }^{29}$ In general practice the boundary of acceptable professional intervention is better defined, with the consultation remaining central to the values and behaviour of general practitioners. The common agenda is served in different, but overlapping ways, as illustrated in table 2 .

\section{Obstacles}

Table 3 summarises some of the potential and actual obstacles to the development of a close relationship between general practice and public health medicine. 
Table 2 The common agenda and illustration of the two approaches

\begin{tabular}{|c|c|c|}
\hline Public health approach & Agenda & Primary care approach \\
\hline $\begin{array}{l}\text { - Serve whole } \\
\text { population }\end{array}$ & $\begin{array}{l}\text { Improve health and } \\
\text { prevent disease }\end{array}$ & $\begin{array}{l}\text { - Serve patients on } \\
\text { register }\end{array}$ \\
\hline $\begin{array}{l}\text { - Combination of } \\
\text { methods including } \\
\text { social and } \\
\text { environmental policy } \\
\text { change } \\
\text { - Mass approaches to } \\
\text { education }\end{array}$ & & $\begin{array}{l}\text { - Focus on patients' } \\
\text { illnesses and risk } \\
\text { factors } \\
\text { - Prevent by medical } \\
\text { intervention }\end{array}$ \\
\hline $\begin{array}{l}\text { Educate educators } \\
\text { and policy makers }\end{array}$ & & $\begin{array}{l}\text { - Lifestyle change by } \\
\text { education }\end{array}$ \\
\hline $\begin{array}{l}\text { - Seek expansion of } \\
\text { funding base for } \\
\text { prevention }\end{array}$ & & $\begin{array}{l}\text { Undertake specific, } \\
\text { but increasing range } \\
\text { of activities in } \\
\text { prevention }\end{array}$ \\
\hline $\begin{array}{l}\text { Take responsibility } \\
\text { for organisational } \\
\text { aspects at a district/ } \\
\text { regional level }\end{array}$ & & \\
\hline $\begin{array}{l}\text { - Evaluation of the } \\
\text { structure, process and } \\
\text { outcome of services }\end{array}$ & $\begin{array}{l}\text { Effectiveness and } \\
\text { efficiency of services }\end{array}$ & $\begin{array}{l}\text { - Audit of clinical work } \\
\text { and practice } \\
\text { organisation }\end{array}$ \\
\hline $\begin{array}{l}\text { Based primarily on } \\
\text { epidemiological and } \\
\text { demographic data, } \\
\text { and on economic } \\
\text { concepts }\end{array}$ & & $\begin{array}{l}\text { - Based partly on } \\
\text { subjective views of } \\
\text { staff and patients }\end{array}$ \\
\hline $\begin{array}{l}\text { Emphasis on needs of } \\
\text { those who make no } \\
\text { demand }\end{array}$ & $\begin{array}{l}\text { Assessment of health } \\
\text { needs }\end{array}$ & $\begin{array}{l}\text { Based mainly on } \\
\text { demands of patients } \\
\text { and contractual } \\
\text { obligations }\end{array}$ \\
\hline $\begin{array}{l}\text { Focus on disease } \\
\text { causes; means of } \\
\text { disease prevention, } \\
\text { and on processes and } \\
\text { outcomes of health } \\
\text { care }\end{array}$ & Research & $\begin{array}{l}\text { - Focus on } \\
\text { management of } \\
\text { common health } \\
\text { problems, and on } \\
\text { structures and } \\
\text { processes of primary } \\
\text { health care }\end{array}$ \\
\hline $\begin{array}{l}\text { Develop local health } \\
\text { policy and adapt and } \\
\text { implement national } \\
\text { and regional health } \\
\text { policy }\end{array}$ & $\begin{array}{l}\text { Policy making and } \\
\text { implementation }\end{array}$ & $\begin{array}{l}\text { Develop practice } \\
\text { policy, and adopt and } \\
\text { implement health } \\
\text { authority policy }\end{array}$ \\
\hline
\end{tabular}

\section{Towards collaboration}

Mutual respect, the key to collaboration, requires a clear understanding of the role, and professional and career aspirations, of the other specialty, as well as an appreciation of the constraints of time and resources. For example, career success for public health physicians may result in successful organisational changes, while for GPs it may be measured in terms of patient satisfaction or the financial success of the practice. General practitioners value time spent in consultation and "projects" may be perceived by them as luxuries, but these "projects" may be extremely important to the public health doctor.

There are about 30 general practitioners for each public health doctor in Britain. There is unlikely to be more than one public health doctor involved in primary care for a population of 500000 or more, and usually this responsibility will be a part-time one. ${ }^{14}$ Therefore, the public health doctor may find it more practical to work with managers and administrators, and general practitioners' representatives, rather than joining with general practitioners in solving their "coal-face" problems.

Professionally satisfying practice of primary medical care is based around clinical freedom and the need to do one's best for the consulting patient; clinical judgement being based on personal experience and knowledge, tempered by scientific advances. The outlook of the public health physician is that the needs of those who are not patients are equally important - that is, the services to the actual patient may need to be curtailed to benefit the potential patient. This difference in perspective may cause friction, particularly as providing a service to the potential patient is harder than to the patient at hand.

My view is that equity of service requires more than an equal share; it requires a share proportionate to need, not as expressed in patient demand but as indicated by imperfect measures of need, including ill health. Health inequalities have been a major concern of public health doctors but not of the general practitioner, for inequalities are most visible at the aggregate rather than the individual level. The problem of the inverse care law, so eloquently expounded by a general practitioner, ${ }^{30}$ cannot be solved by the general practitioner alone.

Personal contact, mutual trust, and clear communication of goals and methods are the basis of successful collaborative work. Most public health doctors know about the work of general practitioners and many have some general practice experience. By contrast many general practitioners have a vague concept of the work of public health doctors. A high priority, therefore, is the creation of opportunities for general practitioners to build relationships with public health practitioners. Conferences, seminars, and other large scale educational events may not suffice and smaller scale events such as workshops or informal meetings to discuss real work problems may be preferable.

Demonstrations of effective collaboration may be more effective than discussion. Academic departments, some of which have had or retain close links, have a special responsibility to explore, publicise and emphasise the value of collaboration. However, the debate on the need for public health and general practice collaboration, led by the academically minded, needs broadening, so that a correct

Table 3 Some obstacles to the achievement of a common agenda

Interprofessional

- Persistence of historical rivalries

- Failure to achieve mutal understanding of roles and goals

- Inequality of esteem - perceived or actual

- Unrealistic expectations

Administrative

- Mismatch between the geographical areas served by public health doctors and general practitioners

- Tension created by the overlap in the role of public health doctors and general practitioners as purchasers

Philosophical and ethical

- Conflict between need based and demand based approaches to care

- Conflict between immediate needs of the patient and those of potential patients

- Conflict between priority setting and rationing, and doing the best for the patient

Practical

- Shortage of staff in public health medicine in relation to needs at primary care level

- Rapidly increasing sphere of responsibility of general practitioners 
and widely shared analysis of the costs, benefits and obstacles to collaboration can be achieved.

The paths of public health medicine and general practice need to converge but this goal will be achieved only with difficulty. Organisational change can lead in unexpected directions, as the 1974 reorganisation of the NHS showed. Postgraduate training structures and programmes in public health medicine and general practice which now run in parallel, with little exchange of trainees, staff and ideas, offer a potential lever for change. ${ }^{31}$ The more recent administrative reorganisation of the NHS, with its purchaser/ provider split will, paradoxically, forge a new and closer relationship between the specialties of public health medicine and general practice. For enthusiasts of public health oriented primary health care, the moment has come.

I thank Dr Judith Rankin for assistance in the literature review, Dr Tim van Zwanenberg and Professor Roger Jones for ideas and comment, and Mrs Lorna Hutchinson for preparing the manuscript.

\section{RAJ BHOPAL}

Department of Epidemiology and Public Health The Medical School, University of Newcastle upon Tyne, Nervcastle upon Tyne. NE2 $4 H H$

\section{Member of $\mathcal{F E C H}$ Editorial Board}

1 Jarman B, Cumberlege J. Developing primary health care. BMf 1987;294: 1005-8.

2 Working Party of the Royal College of General Practitioners. Promoting prevention. Exeter, Royal College of General Practitioners, 1983. Occasional Paper 22.

3 Secretaries of State for Social Services. Promoting better health. London, HMSO, 1987.

4 NHS Executive. Developing NHS purchasing and GP Fundholding. London, Department of Health, 1994.
5 Liddell A. Developing NHS purchasing and GP Fundholding. Leeds, NHS Executive, 1994. Executive letter EL(94)79.

6 Secretaries of State for Health. Working for patients. London, HMSO, 1989.

Committee of Inquiry. Public health in England. Report of the Committee of Inquiry into the future development of the public health function. London, HMSO, 1988.

8 NHS Management Executive. Public health: responsibilities of the NHS and the role of others. Leeds, NHS Management Executive, 1993. HSG(93)56.

Joint Working Party on the Integration of Medical Work. Community medicine in Scotland. Edinburgh, HMSO, 1973.

10 Parry KM. Community practice. I Roy Coll Gen Pract 1977;27:327-33.

11 Tudor-Hart J. Community general practitioners. BMf 1984;288:1670-73.

12 Mant D, Anderson P. Community general practitioner. Lancet 1985;ii $114-17$

13 Stone DH. Primary care, community medicine and prevention: a convergence of needs. F Roy Coll Gen Pract 1987;37:218-20.

14 Russell EM. Community medicine and primary care in Scotland. Community Medicine 1988,10:112-16.

15 Hart JT. A new kind of doctor: the general practitioner's part in the health of the community. London, Merlin Press Ltd, 1988.

16 Ashton J. Public health and primary care: towards a common agenda. Public Health 1990;104:387-98.

17 Paris JAG, Wakeman AP, Griffiths RK. General practitioners and public health. Public Health 1992;106:357-66.

18 Hannay DR. Primary care and public health: too far apart. BMF 1993;307: 516-17.

19 Kark SL Epidemiology and community medicine. New York, Appleton-Century-Crofts 1974

20 Mullan F. Community-oriented primary care. N Eng $\mathcal{f}$ Med 1982;307: 1076-78.

21 Abramson JH. Application of epidemiology in community oriented primary care. Public Health Rep 1984;99:437-42.

22 Abramson JH. Community-oriented primary care - strategy, approaches, and practice: a review. Public Health Rev 1988;16:35-98.

23 Sundwall DN, Tavani C. The role of public health in providing primary care for the medically underserved. Public Health Rep 1991;106:2-5.

24 Booth CC. Research and the general practitioner. BMf 1987;295:1614-19.

25 Horder J. Alma Ata declaration. BMF 1983;286;191-4.

26 Hellberg H. Health for all and primary health care in Europe. Public Health 1987; 101:151-7.

27 Morley D, Rohde J, Williams G. Practising health for all. Oxford, Oxford University Press, 1983.

28 Knowles JH. Community medicine: an overview. In: Latham W, ed. The future of academic community medicine in developing countries. The Rockerfeller Foundation, 1979.

29 Bhopal RS. Public health medicine and purchasing health care. BMF 1993; 306:381-2.

30 Hart JT. The inverse care law. Lancet 1971;i:405-12.

31 Dlugolecka $M$. Testing the water: a GP vocational training scheme rotation in community medicine. Public Health 1989;103:259-61. 